\title{
Cathodic Behaviour of Cysteine at a Platinum Electrode
}

\author{
M. Fátima Barroso, Teresa Santos, M. Goreti F. Sales, \\ Cristina Delerue-Matos and M. Carmo V. F. Vaz* \\ Requimte/Instituto Superior de Engenharia do Porto, \\ Rua Dr. António Bernardino de Almeida $n^{\circ} 431$, 4200-072 Porto, Portugal
}

\begin{abstract}
The electroreduction behaviour of cysteine was investigated using cyclic, square wave and differencial pulse voltammetric techniques at a platinum working electrode.

The reduction of cysteine occurs at a potential of $-0.36 \mathrm{~V}$ independent of $\mathrm{pH}$. It is a reversible process, controlled mainly by diffusion and in the mechanism of reduction 1 electron per molecule is involved. Using the voltammetric techniques: Cyclic Voltammetry, Square Wave Voltammetry and Differencial Pulse Voltammetry, different parameters $(\mathrm{pH}$, frequency, step potential, pulse amplitude, scan rate) were optimized in order to develop an electrochemical procedure for determination of cysteine in pharmaceutical products. The repeatability, reproducibility, precision and accuracy of the methods were studied. No electroactive interferences from the excipient were found in the pharmaceutical compounds.
\end{abstract}

Keywords: cysteine, voltammetry, platinum electrode, pharmaceuticals, reduction.

\section{Introduction}

Cysteine (Cys) (2-amino-3-mercaptopropanoic acid) is a thio-containing compound (Fig. 1) biologically important in living systems [1], as an active site in the catalytic activity of enzyme and it's found in the structure of vasopressin, an antidiuretic hormone [2]. This substance is involved in a variety of important cellular functions, such as protein synthesis, detoxification and metabolism. Disorders of Cys metabolism include cystinosis, an antosomal recessive disease produced by a defect in lysosomal transport and cystinuria, a common heritable disorder of amino acids transport $[3,4]$. Furthermore, plasma thiol groups have been shown to be susceptible to oxidative damage and, therefore, can serve as diagnostic markers for cardiovascular diseases [5]. Cys has several pharmaceutical applications; it is used in some antibiotics and for treatment of skin damages [6] and as radioprotective agent [7].

\footnotetext{
*Corresponding author. E-mail address: mcv@isep.ipp.pt
} 
Cys is added to wheat flour by the baking and pasta industry to improve dought flexibility, which improves the baked product and reduces baking time. It is the major component of the recipe for the meaty flavouring used in savoury snacks and pet foods and it is effective as an antioxidant in natural fruit juices and other foodstuffs [8] under the E-number 910 or 920.

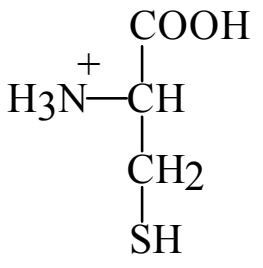

Figure 1. Structural formula of Cys.

Different analytical methods have been developed to quantify Cys and there metabolites in biological matrices (urine, human salivary, blood), pharmaceutical preparation and foods. The most commonly employed techniques are the chromatographic such as liquid chromatography (LC) [9-15], and gas chromatography (GC) [16]. Many of these methods require several manipulation steps which are time-consuming and use significant amounts of solvent, and they require sophisticated instrumentation and training. Considering that voltammetric techniques are relatively simple to apply, quite rapid and reasonably cheap, several procedures for quantification of Cys based on electrochemical methods have been developed.

The electrochemical oxidation of Cys has been the subject of many investigations. This amino acid can be easily oxidized to cystine by suitable oxidizing agents [17] or using platinum, gold, vitreous carbon [8,18-19] but the oxidation of Cys occurs at high potentials. Mercury electrodes are also used [17, $20]$, but the formation of mercury compounds is today an environmental concern. The aim of this work is the study of the electrochemical reduction behaviour of Cys at a platinum electrode using voltammetric techniques, and the development of an analytical procedure to quantify Cys in pharmaceutical compounds.

\section{Experimental}

\section{Equipment}

All voltammetric measurements were performed using a computer controlled pontentiostat/galvanostat Autolab PSTAT (EcoChemie, Netherlands), and a Metrohm VA Stand containing a three-electrode cell (all Metrohm): a platinum electrode or a glassy carbon electrode as a working electrode, a $\mathrm{Ag} / \mathrm{AgCl} / \mathrm{KCl}$ $3.00 \mathrm{~mol} \mathrm{~L}^{-1}$ reference electrode and a glassy carbon rod counter electrode. The system was controlled by means of a General-Purpose Electrochemical System (GPES) software package, version 3.0, from Ecochemie.

$\mathrm{pH}$ was measured with a Metrohm E-520 pH meter with combined electrode.

Solid working electrodes were mechanically cleaned before each experiment by polishing its surface using a polishing kit (Metrohm 6.2802.010), first with $\alpha$ $\mathrm{Al}_{2} \mathrm{O}_{3}(0.3 \mu \mathrm{m})$ until a shining surface was obtained, and after with only water. 


\section{Reagents and solutions}

Cys (Fluka) was purchased from Riedel-deHaen and used without further purification. All other chemical were Merck pro-analysis grade and all solutions were prepared using purified water (conductivity $<0.1 \mu \mathrm{S} \mathrm{cm}^{-1}$ ) obtained from a Barnstread E-pure 4 system.

The supporting electrolyte in voltammetric determination was $\mathrm{KNO}_{3}$ solution $\left(0.5 \mathrm{~mol} \mathrm{~L}^{-1}\right)$. The $\mathrm{pH}$ of the solutions was adjusted with $0.1 \mathrm{~mol} \mathrm{~L}^{-1} \mathrm{HCl}$ and 0.1 mol L ${ }^{-1} \mathrm{NaHO}$.

\section{Standard and sample preparations}

Stock solutions of Cys $\left(1.0 \times 10^{-2} \mathrm{~mol} \mathrm{~L}^{-1}\right)$ were prepared with an exact weight of the pure amino acid dissolved in water. The standard solutions used for the optimization studies and plotting calibration curves were prepared by dilution of these stock solutions with water. These solutions are stable for at least 1 week if kept in the dark at $+4{ }^{\circ} \mathrm{C}$.

Five tablets of Phakan (each tablet contains $0.290 \mathrm{mg}$ of Cys) were accurately weighed and finely powdered and mixed. An adequate amount of this powder was weighed, and transferred into a $50 \mathrm{~mL}$ calibrated flask; the volume was completed with water. The content of the flask was sonicated for $5 \mathrm{~min}$ to achieve complete dissolution. Appropriate solutions were prepared by taking suitable aliquots and diluting with $\mathrm{KNO}_{3}$ solution.

\section{Procedures}

The electrochemical behaviour of $5.0 \times 10^{-4}$ mol L ${ }^{-1}$ Cys was studied in $\mathrm{KNO}_{3}$ solutions $\left(0.5 \mathrm{~mol} \mathrm{~L}^{-1}\right.$ ionic strength) over a wide $\mathrm{pH}$ range $(3.4-10.9)$ at platinum electrode, using three voltammetric techniques: Cyclic Voltammetry (CV), Square Wave Voltammetry (SWV) and Differential Pulse Voltammetry (DPV). A known volume of Cys solutions, together with $10.0 \mathrm{~mL}$ of $\mathrm{KNO}_{3}$ solution, was purged with purified nitrogen for $2 \mathrm{~min}$. The electrode surface was polished between two consecutive scans. The scan was conducted from $0.0 \mathrm{~V}$ to $1.0 \mathrm{~V}$.

\section{Interferences}

Various possible interfering substances, citric acid, ascorbic acid, sucrose and glutamic acid, all of which commonly present in the pharmaceutical products, were tested under the same experimental conditions. The effect of interference with different concentrations on the peak current of a solution containing $5.0 \times 10^{-4} \mathrm{~mol} \mathrm{~L}^{-1}$ of Cys was studied. It was generally considered to interfere with the analysis when its presence produced a variation in the peak current of the sample larger than 5\%. 


\section{Results and discussion}

\section{Preliminary study}

In order to obtain some information of the electrochemical reduction behaviour of Cys in this preliminary study, a glassy carbon electrode was used over a wide $\mathrm{pH}$ range $(3.4-10.9)$. The square wave voltammograms of $5.0 \times 10^{-4} \mathrm{~mol} \mathrm{~L}^{-1} \mathrm{Cys}$ in $\mathrm{KNO}_{3}$ solution showed that this amino acid presents a reduction peak at a potential of $-1.38 \mathrm{~V}$ vs. $\mathrm{AgCl} / \mathrm{Ag}$ (Fig. 2). The drawback of this solid electrode is that the reduction of this amino acid occurs at a high negative potential. Using the platinum electrode, Cys presents electrochemical reduction activity. At the same conditions, the scans showed in the cathodic direction a very well-defined peak at a potential of $-0.36 \mathrm{~V}$ vs. $\mathrm{AgCl} / \mathrm{Ag}$ independent of $\mathrm{pH}$ (Fig. 2). So it was selected, as working electrode, a platinum electrode.

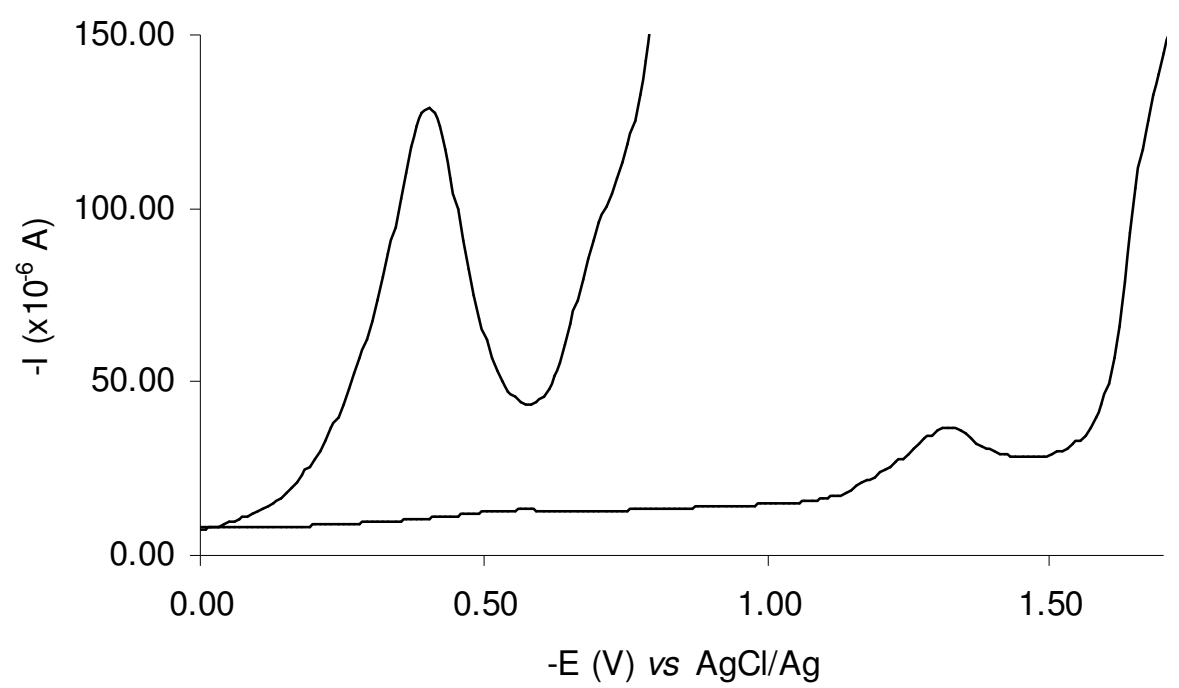

Figure 2. Square wave voltammograms of $5.0 \times 10^{-4}$ mol L ${ }^{-1}$ Cys in $\mathrm{KNO}_{3}\left(0.5 \mathrm{~mol} \mathrm{~L}^{-1}\right)$ solution at: A) glassy carbon electrode, and B) platinum electrode.

\section{Cyclic Voltammetry}

The reversibility of Cys reduction was studied using CV. The voltammograms carried out showed one single well-defined peak in the cathodic and anodic scan, indicating that the reaction is a reversible process. The peak current of the cathodic $\left(i_{p c}\right)$ and anodic scan $\left(i_{\mathrm{pa}}\right)$ of Cys were measured and it was verified that $\left|i_{p c} / i_{p a}=1\right|$, this way probing the reversibility of the electroreduction of Cys [21].

The influence of the scan rate on the cathodic peak current $\left(i_{\text {pc }}\right)$ was studied within the range $0.010-0.50 \mathrm{~V} \mathrm{~s}^{-1}$ (Fig. 3) for $5.0 \times 10^{-4}$ mol L ${ }^{-1} \mathrm{Cys}$ in $\mathrm{KNO}_{3}$ solution at $\mathrm{pH}$ 4.4. The cycles carried out within the increased values of scan rates produced a linear relationship with the square root of the scan rate. This indicates that the process at the surface of the electrode was mainly controlled by diffusion following eq. 1 :

$$
-\mathrm{i}_{\mathrm{pc}}\left(\times 10^{-5}\right)=2.03 \times 10^{-1} v^{1 / 2}+5.04 \times 10^{-6}
$$


where $i_{p c}$ is the peak current of cys (Ampere); $v$ is the scan rate $\left(\mathrm{mV} \mathrm{s}^{-1}\right)$, with a correlation coefficient (r) of 0.997.

Using $\mathrm{CV}$ at a platinum working electrode, the number of electrons was determined by the application of Randles and Sevcik mathematical equation [21] (eq. 2):

$$
\frac{\mathrm{i}_{\mathrm{pc}(\mathrm{cys})}}{\mathrm{i}_{\mathrm{pc}(\mathrm{Fe})}}=\frac{\mathrm{n}_{(\mathrm{cys})}{ }^{3 / 2} \mathrm{D}_{(\mathrm{cys})}{ }^{1 / 2} \mathrm{C}_{(\mathrm{cys})}}{\mathrm{n}_{(\mathrm{Fe})}{ }^{3 / 2} \mathrm{D}_{(\mathrm{Fe})}{ }^{1 / 2} \mathrm{C}_{(\mathrm{Fe})}}
$$

where $\mathrm{i}_{\mathrm{pc}}(\mathrm{Cys}), \mathrm{i}_{\mathrm{pc}}(\mathrm{Fe})$ are the peak current $(\mathrm{A}) ; \mathrm{n}_{(\mathrm{cys})}, \mathrm{n}_{(\mathrm{Fe})}$ are the number of electrons; $\mathrm{D}_{(\mathrm{cys})}, \mathrm{D}_{(\mathrm{Fe})}$ are the diffusion coefficients $\left(\mathrm{cm}^{2} \mathrm{~s}^{-1}\right)$; and $\mathrm{C}_{(\mathrm{cys})}, \mathrm{C}_{(\mathrm{Fe})}$ are the same concentration $\left(\mathrm{mol} \mathrm{L} \mathrm{L}^{-1}\right)$ in the same solvent, of Cys and hexacyanoferrate (III), respectively. This equation was applied assuming that $\mathrm{D}_{(\mathrm{Cys})}$ is equal to $\mathrm{D}_{(\mathrm{Fe})}$. Knowing that potassium hexacyanoferrate (III) involved one electron per molecule [21], and applying the Randles and Sevcik equation, the number of electrons involved in the reduction of Cys was $1.29 \pm 0.05$ electron per molecule.

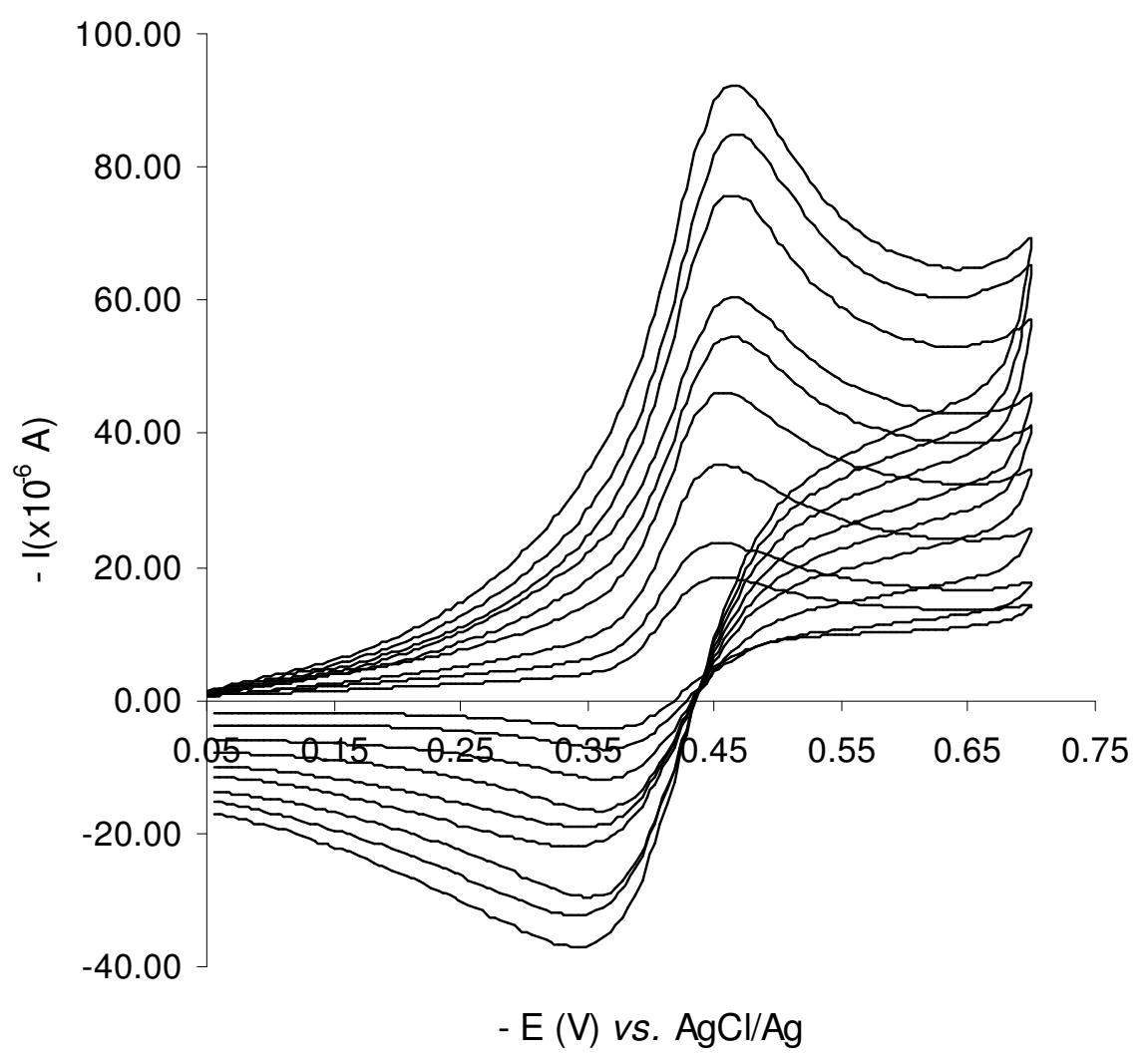

Figure 3. Cyclic voltammograms of $5.0 \times 10^{-4}$ mol L ${ }^{-1}$ Cys solution in $\mathrm{KNO}_{3}$ solution with a platinum electrode: $\mathrm{A} \uparrow$ (sense of increase scan rate) $0.010 \mathrm{~V} \mathrm{~s}^{-1}$ to $0.50 \mathrm{~V} \mathrm{~s}^{-1}$. 
Using a scan rate of $0.40 \mathrm{~V} \mathrm{~s}^{-1}$ and $\mathrm{pH} 4.4$, a calibration curve was plotted that had a linear response from $2 \times 10^{-4}$ to $1.0 \times 10^{-3}$ mol L ${ }^{-1}$ Cys in $\mathrm{KNO}_{3}$ solution with $\mathrm{r}=0.998$, (eq. 3):

$$
-\mathrm{i}_{\mathrm{pc}}\left(\times 10^{-6}\right)=5.84 \pm 0.08\left(\times 10^{-4}\right) \mathrm{C}-9.44 \pm 0.08\left(\times 10^{-6}\right)
$$

where $i_{p c}$ is the peak current of cys (Ampere); $C$ is the Cys concentration (mol $\left.\mathrm{L}^{-1}\right)$.

\section{Square Wave Voltammetry}

After knowing the electroreduction behaviour of Cys, a SWV technique was used in order to evaluate the influence of $\mathrm{pH}$, frequency $(f)$, step potential and pulse amplitude on the peak shape and peak height.

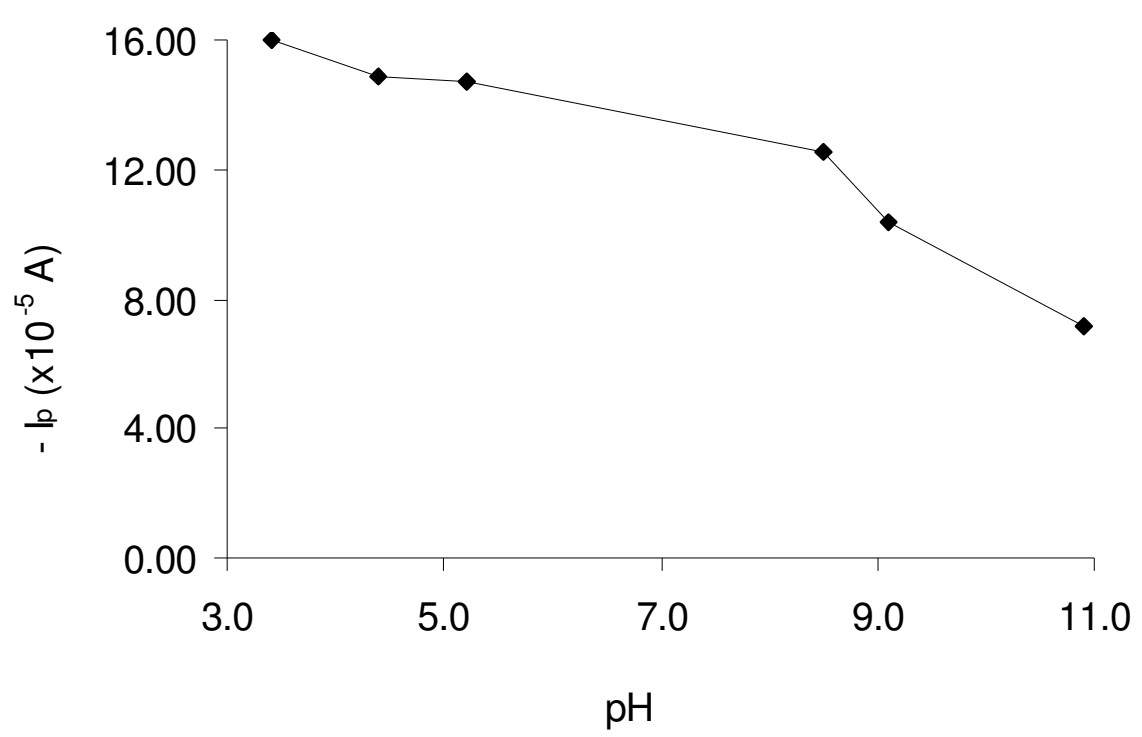

Figure 4. Influence of $\mathrm{pH}$ on the intensity of peak current of $5 \times 10^{-4} \mathrm{~mol} \mathrm{~L}^{-1} \mathrm{Cys}$.

The influence of $\mathrm{pH}$ on the reduction of $5.0 \times 10^{-4} \mathrm{~mol} \mathrm{~L}^{-1} \mathrm{Cys}$ was investigated using $\mathrm{KNO}_{3}$ solutions over a wide $\mathrm{pH}$ range $(3.4-10.9)$ and a frequency of 50 Hz. It was verified that Cys presents electrochemical activity in every range of pH studied, having a maximum peak current at pH 3.4 (Fig. 4). However, for the next studies it was chosen the $\mathrm{pH} 4.4$; with this $\mathrm{pH}$ the peak is more well-defined and repeatability and reproducibility are higher.

The frequency was varied from 10 to $250 \mathrm{~Hz}$. $\mathrm{i}_{\mathrm{p}}$ increased with the frequency until $200 \mathrm{~Hz}$; above this value the peak became distorted. Hence, this frequency was chosen for all subsequent studies.

The influence of step potential was studied in the range of 0.001 to $0.150 \mathrm{~V}$, presenting an $i_{p}$ maximum at $0.001 \mathrm{~V}$; above this value $i_{p}$ decreased. The pulse amplitude parameter was evaluated from $0.001 \mathrm{~V}$ to $0.100 \mathrm{~V}$ presenting a maximum activity at $0.100 \mathrm{~V}$. For the next analysis were used step potential of $0.001 \mathrm{~V}$ and pulse amplitude $0.100 \mathrm{~V}$. 
With the optimised experimental conditions ( $\mathrm{pH}=4.4 ; f=200 \mathrm{~Hz}$; step potential $=0.001 \mathrm{~V}$; pulse amplitude $=0.100 \mathrm{~V}$ ) linearity studies were performed on peak current and Cys concentration (Fig. 5) within the range of $8.0 \times 10^{-5}$ to $1.0 \times 10^{-3}$ mol L ${ }^{-1}$ below the eq. 4 :

$$
-\mathrm{i}_{\mathrm{pc}}\left(\times 10^{-6}\right)=5.6 \pm 0.2\left(\times 10^{-4}\right) \mathrm{C}-11.5 \pm 0.9\left(\times 10^{-6}\right)
$$

where $\mathrm{i}_{\mathrm{pc}}$ is the peak current of cys (Ampere); $\mathrm{C}$ is the Cys concentration (mol $\mathrm{L}^{-1}$ ), with $\mathrm{r}=0.997$.

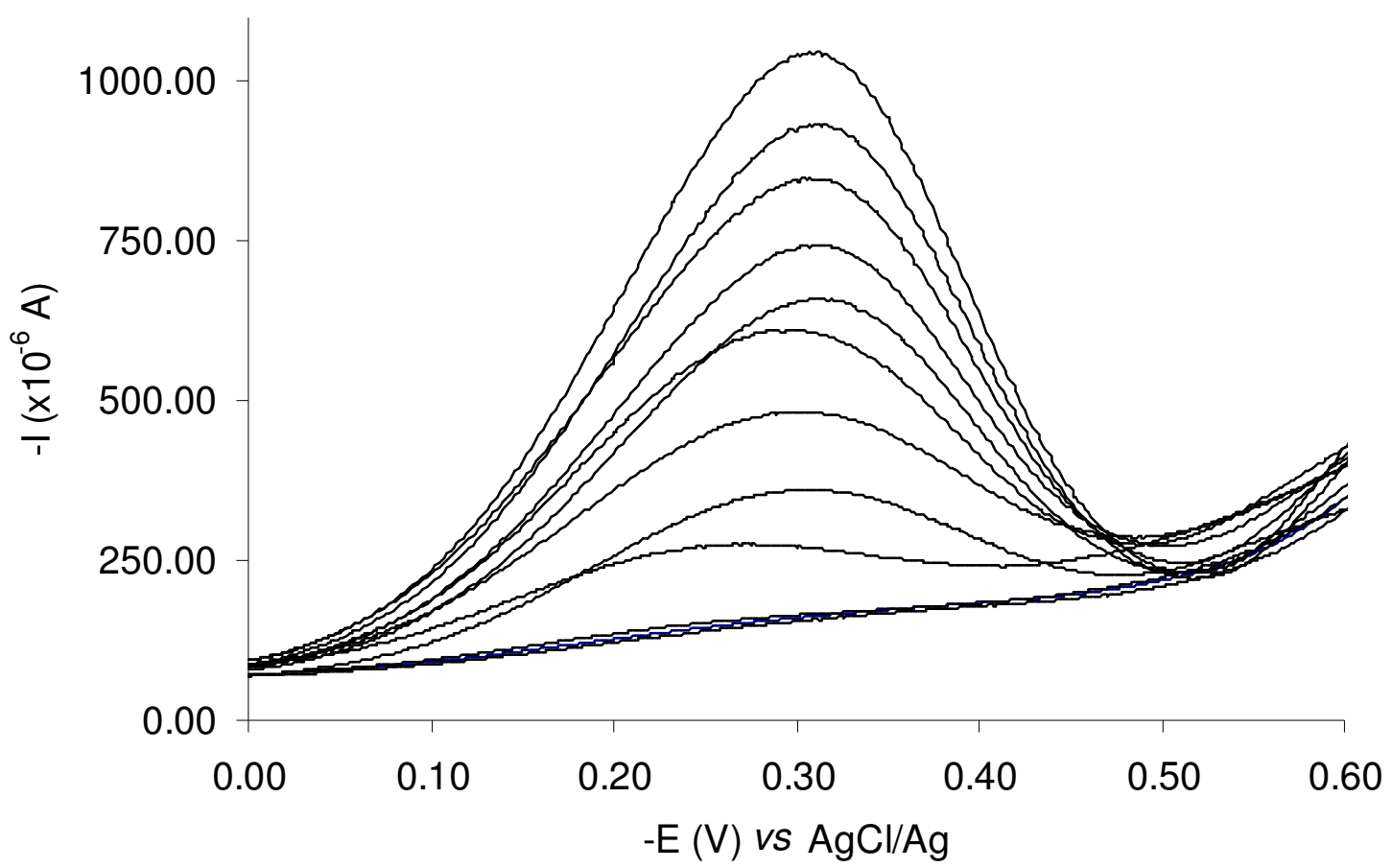

Figure 5. Square wave voltammograms of standard solutions of Cys at platinum electrode $(\mathrm{pH} 4.4 ; f=200 \mathrm{~Hz}) \mathrm{A} \uparrow$ (sense of increase of Cys concentration): $\left(8 \times 10^{-5}\right.$; $9 \times 10^{-5} ; 1.0 \times 10^{-4} ; 2.0 \times 10^{-4} ; 4.0 \times 10^{-4} ; 5.0 \times 10^{-4} ; 6.0 \times 10^{-4} ; 7.0 \times 10^{-4} ; 8.0 \times 10^{-4}$ and $1.0 \times 10^{-3}$ $\left.\mathrm{mol} \mathrm{L}{ }^{-1}\right)$.

\section{Differential Pulse Voltammetry (DPV)}

Using DPV (Fig. 6), the parameters step potential and pulse amplitude were optimized. The step potential was studied in the range of $0.002 \mathrm{~V}$ to $0.010 \mathrm{~V}$ obtaining a maximum peak current with the value $0.007 \mathrm{~V}$ for the step. The pulse amplitude was changed within $0.001 \mathrm{~V}$ and $0.100 \mathrm{~V}$ with a maximum at $0.100 \mathrm{~V}$. With this technique a good linearity was obtained within the $\mathrm{i}_{\mathrm{pc}}$ and concentration of Cys $\left(2.0 \times 10^{-5}\right.$ to $\left.1.0 \times 10^{-3} \mathrm{~mol} \mathrm{~L}^{-1}\right)$ following eq. 5 :

$$
-\mathrm{i}_{\mathrm{pc}}\left(\times 10^{-6}\right)=11.30 \pm 0.02\left(\times 10^{-4}\right) \mathrm{C}-5.6 \pm 0.6 \times 10^{-6}
$$

where $i_{p c}$ is the peak current of cys (Ampere); $\mathrm{C}$ is the Cys concentration (mol $\mathrm{L}^{-1}$ ), with $\mathrm{r}=0.996$. 
Table 1 presents the calibration data obtained using the optimised condition for the three voltammetric techniques used. Each point of calibration curve corresponds to the mean value obtained from 10 independent measurements. The limit of detection (LOD) and limit of quantification (LOQ) values were calculated according to Mocak [22].

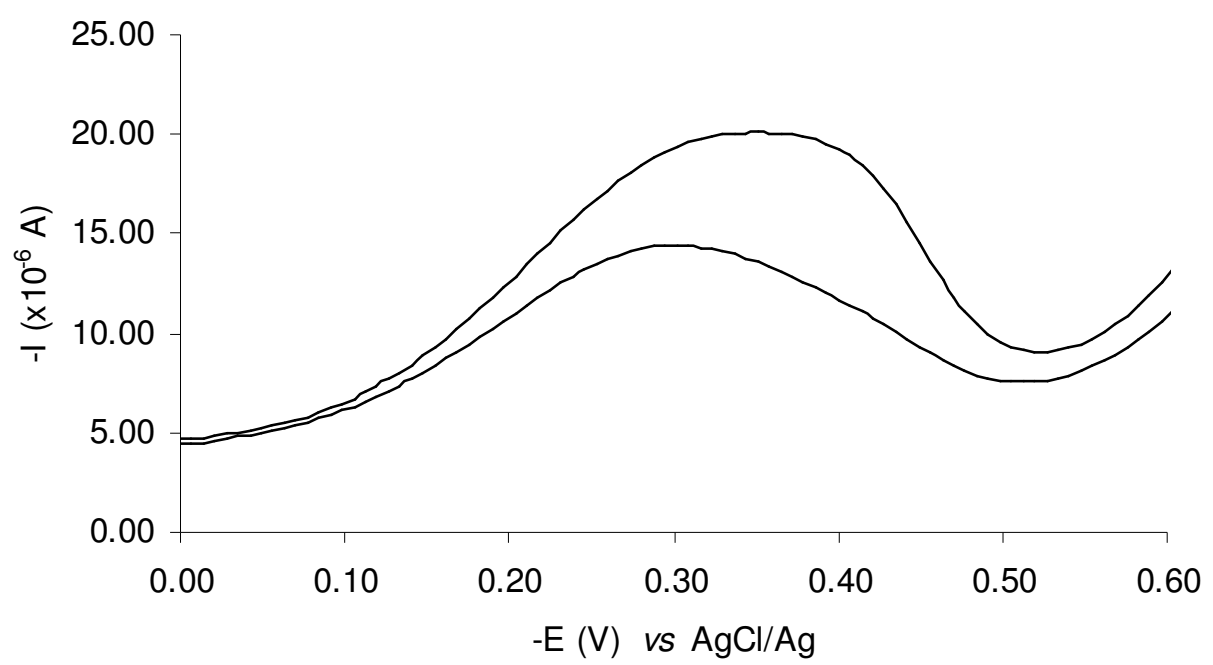

Figure 6. Differential pulse voltammograms of standard solutions of Cys at platinum electrode. A $-1.0 \times 10^{-4} \mathrm{~mol} \mathrm{~L}^{-1}, \mathrm{~B}-2.0 \times 10^{-4} \mathrm{~mol} \mathrm{~L}^{-1}$.

Table 1. Mean values ( \pm standard deviation) of 10 independent calibrations of Cys using CV, SWV and DPV.

\begin{tabular}{lccc}
\hline & $C V$ & $S W V$ & $D P V$ \\
\hline Linear concentration range $\left(\times 10^{-4} \mathrm{~mol} \mathrm{~L}^{-1}\right)$ & $2.0-10.0$ & $0.80-10.0$ & $0.20-10.0$ \\
Slope $\left(\times 10^{-4} \mathrm{~A} \mathrm{~mol}^{-1} \mathrm{~L}\right)$ & $5.84( \pm 0.08)$ & $5.6( \pm 0.2)$ & $11.30( \pm 0.02)$ \\
Intercept $\left(\times 10^{-6} \mathrm{~A}\right)$ & $9.44( \pm 0.08)$ & $11.5( \pm 0.9)$ & $5.6 \pm(0.6)$ \\
Correlation coefficient $(\mathrm{n}=10)$ & 0.998 & 0.997 & 0.996 \\
LOD $\left(\times 10^{-6} \mathrm{~mol} \mathrm{~L}^{-1}\right)$ & 4.0 & 8.0 & 4.5 \\
LOQ $\left(\times 10^{-5} \mathrm{~mol} \mathrm{~L}^{-1}\right)$ & 1.2 & 2.4 & 1.4 \\
RSD $\%{ }^{\text {a) }}$ & 2.3 & 1.5 & 2.0 \\
\hline${ }^{\text {a) }}$ Concentration of Cys equal to $5.0 \times 10^{-4} \mathrm{~mol} \mathrm{~L}^{-1}$. LOD: Limit of detection; LOQ: Limit of quantification.
\end{tabular}

\section{Repeatability, reproducibility and accuracy}

Repeatability, reproducibility and accuracy of Cys measurements under optimised conditions using the three voltammetric techniques were confirmed after three successive determinations of two different concentrations of Cys over 
one day (intraday assay) and over a week (interday assay). Results obtained are reported in Table 2 and point out the good precision and accuracy of Cys electrochemical measurements.

Table 2. Analytical precision and accuracy of Cys assays by the proposed voltammetric procedure.

\begin{tabular}{|c|c|c|c|c|c|c|c|c|}
\hline \multirow{2}{*}{$\begin{array}{l}\text { Concentration } \\
\left(\times 10^{-4} \mathrm{~mol} \mathrm{~L}^{-1}\right)\end{array}$} & \multicolumn{4}{|l|}{ Intraday $^{a}$} & \multicolumn{4}{|l|}{ Interday $^{b)}$} \\
\hline & $\begin{array}{l}\text { Found } \\
\left(\times 10^{-4} \mathrm{~mol} \mathrm{~L}^{-1}\right)\end{array}$ & $\begin{array}{l}\mathrm{R} \\
(\%)\end{array}$ & Bias $(\%)$ & $\begin{array}{l}\text { RSD } \\
(\%)\end{array}$ & $\begin{array}{l}\text { Found } \\
\left(\times 10^{-4} \mathrm{~mol} \mathrm{~L}^{-1}\right)\end{array}$ & $\mathrm{R}(\%)$ & $\begin{array}{l}\text { Bias } \\
(\%)\end{array}$ & $\begin{array}{l}\text { RSD } \\
(\%)\end{array}$ \\
\hline \multicolumn{9}{|l|}{ CV method } \\
\hline 5.5 & 5.3 & 96.4 & -3.6 & 1.2 & 5.2 & 94.5 & -5.5 & 2.9 \\
\hline 8.6 & 8.9 & 103.5 & +3.5 & 3.7 & 8.5 & 98.8 & -1.2 & 3.0 \\
\hline \multicolumn{9}{|l|}{ SWV method } \\
\hline 5.3 & 5.0 & 94.3 & -5.7 & 2.5 & 5.4 & 101.9 & +1.9 & 2.3 \\
\hline 8.2 & 8.0 & 97.6 & -2.4 & 1.8 & 8.1 & 98.7 & -1.2 & 1.5 \\
\hline \multicolumn{9}{|l|}{ DPV method } \\
\hline 6.2 & 6.1 & 98.4 & -1.6 & 2.3 & 6.3 & 101.6 & +1.6 & 1.3 \\
\hline 8.5 & 8.6 & 101.2 & +1.2 & 1.4 & 8.4 & 98.8 & -1.2 & 1.8 \\
\hline
\end{tabular}

\section{Interferences}

To test the efficiency and selectivity of the three proposed analytical method to pharmaceutical formulations, a systemic study was made. Solutions containing a fixed amount of Cys $\left(5.0 \times 10^{-4} \mathrm{~mol} \mathrm{~L}^{-1}\right)$ were spiked with excess amount of each excipient of pharmaceutical preparation under the optimum experimental conditions.

Experiments showed that no serious interference occurred from the addition of the studied compound. However, citric acid and ascorbic acid interfere in the signal of Cys when the concentration of these interferences is $3 \times 10^{-4} \mathrm{~mol} \mathrm{~L}^{-1}$ for citric acid and $8 \times 10^{-4} \mathrm{~mol} \mathrm{~L}^{-1}$ for ascorbic acid. Nevertheless, this is not a problem because these compounds appear in pharmaceuticals in smaller concentration.

\section{Analysis of Cys in pharmaceuticals (Phakan)}

The optimized voltammetric methods were applied to the determination of Cys in pharmaceuticals (Phakan). This analysis was carried out using the three techniques evaluated: (CV, SWV and DPV) and as supporting solutions $\mathrm{KNO}_{3}$ solution. An aliquot of each diluted sample solution was added to the 
voltammetric cell. The quantification of Cys was assessed by analysing samples in three independent measurements and calculated using the calibration curve. Mean values of Cys concentration, standard deviations, and recovery results are presented in Table 3.

Table 3. Voltammetric quantification of Cys in pharmaceutical product (Phakan)

\begin{tabular}{cccc}
\hline $\begin{array}{c}\text { Concentration } \\
\left(\times 10^{-4} \mathrm{~mol} \mathrm{~L}^{-1}\right)\end{array}$ & $\begin{array}{c}\text { Found } \\
\left(\times 10^{-4} \mathrm{~mol} \mathrm{~L}^{-1}\right)\end{array}$ & $\begin{array}{c}\text { Bias } \\
(\%)\end{array}$ & $\begin{array}{c}\text { Recovery } \\
\%)\end{array}$ \\
\hline CV methods & & & \\
0.90 & $0.81 \pm 0.01$ & -10.0 & 97.0 \\
1.00 & $0.93 \pm 0.07$ & -7.5 & 97.0 \\
\hline SWV method & & & \\
0.90 & $0.89 \pm 0.02$ & -1.1 & 97.3 \\
1.66 & $1.90 \pm 0.03$ & +7.8 & 99.8 \\
\hline DPV method & & & \\
0.70 & $0.68 \pm 0.03$ & -2.9 & 83.5 \\
0.80 & $0.83 \pm 0.04$ & +3.75 & 83.5 \\
\hline
\end{tabular}

\section{Conclusions}

On the basis of the electroreduction of Cys at a platinum electrode, three voltammetric procedures were optimized in order to quantify this amino acid in pharmaceuticals. These voltammetric techniques are a good alternative because they are simpler, faster and less expensive, than the classical procedures and were applied directly to the analysis of pharmaceutical products without complex sample preparation such as time-consuming extraction steps.

\section{References}

1. M.F.S. Teixeira, E.R. Dockal, E.T.G. Cavalheiro, Sensors and Actuators B 106 (2005) 619.

2. M.K. Amini, J.H. Khorasani, S.S. Khaloo, S. Tangestaninnejad, Anal. Biochem. 320 (2003) 32.

3. C. Lau, X. Qin, J. Liang, J. Lu, Anal. Chim. Acta 514 (2004) 45.

4. J.J.J. Ruiz-Díaz, A.A.J. Torriero, E. Salinas, E.J. Marchevsky, M.I. Sanz, J. Raba, Talanta 68 (2006) 1343.

5. P.M. Ueland, H. Refsum, L. Brattstrom, in: R.B. Francis Jr. (Ed.) Atherosclerotic Cardiovascular Disease, Hemostasis, and Endothelial Function, Marcel Dekker, New York, 1992, pp. 183.

6. $\quad$ S.A. Wring, J.P. Hart, B.J. Birch, Analyst 117 (1989) 1563. 
7. J. Kulys, A. Drungiliene, Anal. Chim. Acta 243 (1991) 287.

8. T.R. Ralph, M.L. Hitchman, J.P. Millington, F.C. Walsh, J. Electroanal. Chem. 375 (1994) 17.

9. T. Bjellaas, K. Janak, E. Lundanes, L. Kronberg, Xenobiotica 35 (2005) 1003.

10. K.M. Karlsson, L.E.M. Spoof, J.A.O. Meriluolo, Environ. Toxicol. 20 (2005) 381.

11. R. Glowacki, D. Gryglik, K. Kusmierek, E. Bold, Talanta 66 (2005) 534.

12. L. Sunlonsuk, J. Pharm. Biomed. Anal. 25 (2001) 165.

13. M. Castagnola, D. Congiu, G. Denolli, A. Di Núncio, M.B. Fadda, S. Melis, L. Messana, F. Misiti, R. Murlas, A. Olianas, V. Piras, A. Pittau, G. Puddu, J. Chromatogr. B 751 (2001) 153.

14. E. Bramanli, C. Vecoli, D. Neglia, M.P. Pellegrini, G. Raspi, B. Barsacchi, Clin. Chem. 51 (2005) 1007.

15. L. Bosch, A. Alegria, R. Furre, J. Chromatogr. B 831 (2006) 176.

16. H. Orhan, J.N.M. Commandeur, G. Sahir, U. Aypar, A. Gahin, N.P.E. Vermeulen, Xenobiotica 34 (2001) 301.

17. I.M. Kolthoff, C. Barnum, J. Am. Chem. Soc. 62 (1940) 3061.

18. D. Davis, E. Banco, J. Electroanal. Chem. 12 (1966) 254.

19. J.A. Reynaud, B. Malfoy, P. Canesson, J. Electroanal. Chem. 114 (1980) 195.

20. B. Monterroso-Marco, B. López-Ruiz, Talanta 61 (2003) 733.

21. A.M.O. Brett, C.M.A. Brett, "Electroquímica, princípios, métodos, e aplicações” Edições Almedina, Portugal, (1996), pp. 193-204.

22. J. Mocak, A.M. Bond, S. Mitchell, G. Scollary, Pure. Appl. Chem. 69 (1997) 297. 